\title{
PEDIATRIC ORIGINAL ARTICLE Childhood body mass index and height and risk of histologic subtypes of endometrial cancer
}

\author{
J Aarestrup ${ }^{1}$, M Gamborg ${ }^{1}$, LG Ulrich ${ }^{2}$, TIA Sørensen ${ }^{1,3}$ and JL Baker ${ }^{1,3}$
}

BACKGROUND: Endometrial cancer risk factors include adult obesity and taller stature, but the influence of size earlier in life is incompletely understood. We examined whether childhood body mass index (BMl; $\mathrm{kg} \mathrm{m}^{-2}$ ) and height were associated with histologic subtypes of endometrial cancer.

METHODS: From the Copenhagen School Health Records Register, 155505 girls born 1930-1989 with measured weights and heights from 7 to 13 years were linked to health registers. BMI and height were transformed to age-specific z-scores. Hazard ratios (HRs) and 95\% confidence intervals were estimated by Cox regressions.

RESULTS: A total of 1020 endometrial cancers were recorded. BMI was non-linearly associated with all endometrial cancers, oestrogen-dependent cancers and the subtype of endometrioid adenocarcinomas; associations were statistically significant and positive above a $z$-score $=0$ and non-significant below zero. Compared with a 7-year-old girl with a BMI $z$-score $=0$, an equally tall girl who was $3.6 \mathrm{~kg}$ heavier (BMI $z$-score $=1.5$ ) had a hazard ratio $=1.53$ (95\% confidence interval: $1.29-1.82)$ for endometrioid adenocarcinoma. BMI was not associated with non-oestrogen-dependent cancers, except at the oldest childhood ages. Height at all ages was statistically significant and positively associated with all endometrial cancers, except non-oestrogen-dependent cancers. At 7 years, per $\sim 5.2 \mathrm{~cm}$ (1 z-score), the risk of endometrioid adenocarcinoma was 1.18 (95\% confidence interval: 1.09-1.28). Among non-users of unopposed oestrogens, associations between BMI and endometrioid adenocarcinoma strengthened, but no effects on height associations were observed.

CONCLUSIONS: Endometrial carcinogenesis is linked to early-life body size, suggesting that childhood BMI and height may be useful indicators for the risk of later development of endometrial cancer and might aid in the early prevention of obesity-related endometrial cancers.

International Journal of Obesity (2016) 40, 1096-1102; doi:10.1038/ijo.2016.56

\section{INTRODUCTION}

Endometrial cancer is the most common gynaecologic cancer among women in the Western world. ${ }^{1-3}$ Excess body fatness in adulthood is consistently and strongly linked to an increased risk of endometrial cancer among both pre- and post-menopausal women. ${ }^{1,2,4-7}$ It is estimated that $34 \%$ of the global burden of incident endometrial cancer is attributable to excess adult adiposity. ${ }^{8}$

Aetiologically, endometrial cancer is a heterogeneous cancer. ${ }^{9}$ Oestrogen-dependent cancers (type 1) account for $\sim 80 \%$ of endometrial cancers, of which endometrioid adenocarcinoma is the predominant form and the prototype. Non-oestrogendependent cancers (type 2) are less common and account for $\sim 20 \%$ of endometrial cancers. ${ }^{10-12}$ Adiposity is thought to increase the risk of oestrogen-dependent endometrial cancers through an augmented bioavailability of endogenous oestrogens produced by aromatisation of androgens in adipose tissue. ${ }^{13}$ Although less attention has been given to adult stature, evidence suggests that height may increase the risk of endometrial cancer, but specific mechanisms are unknown. ${ }^{1,4,14}$

It is possible that the initiation of endometrial cancer begins early in life; however, associations between early-life body size and subsequent risk of endometrial cancer are inconsistent. Although several studies found indications of positive associations with child and adolescent body size, all used self-reported recalled body size and histological subtypes of endometrial cancer were not examined. ${ }^{15-24} \mathrm{~A}$ few studies examined associations with child height, ${ }^{19,21,23}$ but only one found a significant and positive association. ${ }^{23}$ Therefore, we investigated whether childhood body mass index (BMl; $\mathrm{kg} \mathrm{m}^{-2}$ ) and height were associated with the risk of histological subtypes of endometrial cancer in a populationbased cohort.

\section{SUBJECTS AND METHODS}

\section{Cohort}

The study population was from the Copenhagen School Health Records Register, which contains computerised information on 372636 children. Virtually, all school children in the municipality of Copenhagen, born 19301989, underwent annual mandatory health examinations through 1983 and thereafter only at school entrance and exit, unless the child had specific health requirements. Heights and weights were measured by trained school physicians and nurses with high precision. ${ }^{25}$

Unique government-issued personal identification numbers were assigned to all Danish residents alive in 1968 or born thereafter. ${ }^{26}$ Children who attended school in 1968 or later had their identification number recorded on their health card. If a child left school before this time, the

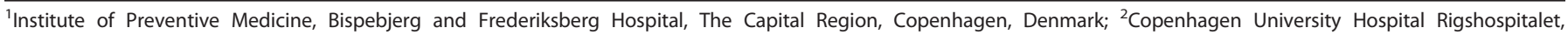

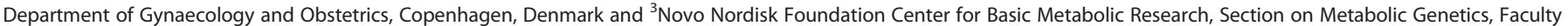

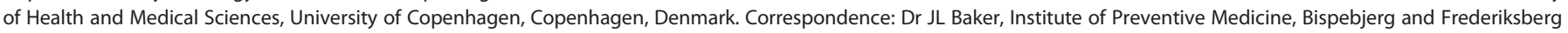
Hospital, Nordre Fasanvej 57, Frederiksberg, 2000, Denmark.

E-mail: jennifer.lyn.baker@regionh.dk

Received 13 August 2015; revised 21 January 2016; accepted 4 March 2016; accepted article preview online 28 April 2016 ; advance online publication, 17 May 2016 
number was retrieved. Via these identification numbers, linkages were made to national health registers for follow-up.

\section{Study variables}

Using the Lamda, Median, Sigma method, BMI and height were transformed into $z$-scores. ${ }^{27}$ BMI $z$-scores were based upon an internal age- and sex-specific reference chosen from a period with a low and stable obesity prevalence. Height $z$-scores were based upon internal sex-, ageand birth cohort-specific references to account for secular increases in height. Z-scores were interpolated or extrapolated within a \pm 12 -month period. $^{28}$

Incident endometrial cancers were identified through linkage to the Danish Cancer Registry, which contains information on cancers from 1943 onwards. ${ }^{29}$ The majority of the cancers are morphologically verified, and due to compulsory notification, the completeness of the registry is high. ${ }^{29,30}$ The International Classification of Disease (ICD) codes version 7 was used until 1994 and version 10 thereafter. Danish Cancer Registry personnel recoded all cancers diagnosed between 1978 and 2004 to ICD-10 and ICD for Oncology codes (ICD-O) version $3 .^{29}$

Endometrial cancers were classified using ICD-10 codes C54.0-C54.1, C54.3-C54.6, C54.9 and C55.9. On the basis of ICD-O-3 morphology codes, sarcomas, carcinoma-sarcomas, very rare endometrial cancers and cancers without information on morphology were excluded from all analyses. The remaining cancers were classified as oestrogen dependent or nonoestrogen dependent, except for a few cancers that could not be classified due to limited morphology information (Table 1).

Vital status was obtained by linkage to the Vital Statistics Register. ${ }^{26}$ Hysterectomy information was obtained by linkage to the Danish National Patient Register, which was established in 1977 and contains information on all hospital discharge diagnoses. ${ }^{31}$ Information on hormone replacement therapy usage was obtained through linkage to the Danish National Prescription Registry, which contains the data on all prescriptions dispensed by Danish pharmacies from 1995 onwards. ${ }^{32}$ Unopposed oestrogens were identified using Anatomical Therapeutic Chemical classification codes (G03CA03 (oestradiol), G03CA04 (oestriol), G03CA53 (oestradiol, combinations), G03CA57 (conjugated oestrogens) and trade names). Women were classified as using unopposed oestrogens if prescriptions were refilled at least twice.

\section{Study population}

Women eligible for this study were born 1930-1989, with an identification number, alive and living in Denmark on 1 January 1978 and aged 18 years or older. Among 184276 girls in the cohort, 21717 did not have an identification number (as identification numbers could not be retrieved for all leaving school before 1968 due to, for example, death, emigration, name changes and possible spelling errors) and 3808 were excluded due to emigration, death or loss to follow-up before age 18 years or 1 January 1978. In addition, women with a hysterectomy before $1978(N=525)$ or age 18 years $(N=5)$, with an endometrial cancer diagnosis before 1978 $(N=10)$, without a date for the endometrial cancer diagnosis $(N=1)$, missing height and/or weight measurements at all childhood ages $(N=2701)$ or with outlying height or BMI $z$-scores at all ages ( $z$-score less than -4.5 or greater than $4.5 ; N=4$ ) were excluded.

Each woman was followed from the age of 18 years or from her age in 1978, whichever came later. Individuals were followed up until a diagnosis of endometrial cancer, hysterectomy, death, emigration, loss to follow-up or 31 December 2012, whichever came first.

\section{Statistical analysis}

Cox proportional hazards regressions were used to examine associations between $\mathrm{BMI}$ and height $z$-scores, with and without mutual adjustment, at each age from 7 to 13 years and the risk of all endometrial cancers, oestrogen-dependent cancers, endometrioid adenocarcinomas and nonoestrogen-dependent cancers, respectively. Age at diagnosis was the underlying time scale, and analyses were stratified by 5-year birth cohorts to allow the baseline hazard to differ by birth cohort.

The linearity of the associations was assessed by linear splines with two knots at $z$-scores of \pm 0.68 corresponding to $\sim 25$ th and 75 th percentiles of the distributions. Statistically significant non-linearity was detected for associations between $\mathrm{BMI}$ and all endometrial cancers, oestrogendependent cancers and endometrioid adenocarcinomas, except at ages 12-13 years. Nonetheless, the overall pattern from the younger ages remained and the results are therefore presented using non-linear models.
To facilitate interpretation, point estimates are presented for $z$-scores of $\pm 0.5, \pm 1.0$ and \pm 1.5 (corresponding to $\sim 7 \mathrm{th}, 16 \mathrm{th}, 31 \mathrm{st}, 69 \mathrm{th}, 84 \mathrm{th}$ and 93 rd percentiles) with a $z$-score of 0 as reference. Deviations from linearity were not detected in the associations between BMI and non-oestrogendependent cancers or between height and all endometrial cancers (except at ages 10-13 years), oestrogen-dependent cancers (except at ages 10-13 years), endometrioid adenocarcinomas and non-oestrogen-dependent cancers. Upon inspection, the significant deviations from linearity revealed only a tendency for a levelling-off in the increased risk among the tallest girls, therefore results are presented using the linear models.

Proportional hazards assumptions were investigated by testing if associations between $\mathrm{BMI}$ and height, respectively, and endometrial cancer differed within categories of age at diagnosis using likelihood ratio tests. In addition, potential interactions of birth cohort with the associations between BMI and height, respectively, and endometrial cancers were investigated using likelihood ratio tests. Violations of the proportional hazards assumption and birth cohort effects were not detected.

To examine the influence of unopposed oestrogen usage on associations between childhood body size and endometrioid adenocarcinoma, a sub-analysis was conducted following women from 1995 onwards. Women were followed until unopposed oestrogen usage, a diagnosis of endometrial cancer, hysterectomy, death, emigration, loss to follow-up or 31 December 2012, whichever came first.

Population-attributable fractions (PAFs) were calculated to estimate the burden of endometrial cancers attributable to childhood overweight (including obesity) in a contemporary population of girls from the United States.

This study was approved by the Danish Data Protection Agency. According to Danish law, ethical approval is not required for register-based studies.

\section{RESULTS}

The study included 155505 women. During 35 years and 4.1 million person-years of follow-up, 1020 women were diagnosed with endometrial cancer. Among these, 920 were oestrogendependent cancers (of which 659 were endometrioid adenocarcinoma), 92 were non-oestrogen-dependent cancers and 8 cancers were not classified as either type. The median age at diagnosis was 61 years (range: 24-82) for all endometrial cancers, 61 years (range: 24-82) for oestrogen-dependent cancers, 62 years (range: 24-82) for endometrioid adenocarcinomas and 66 years (range: 38-79) for non-oestrogen-dependent cancers. The median values of both childhood BMI and height increased with age in childhood (Supplementary Table 1).

Childhood BMI was non-linearly associated with all endometrial cancers, oestrogen-dependent cancers and the subtype of endometrioid adenocarcinoma. At all childhood ages, girls with a BMI $z$-score above 0 had a higher risk of all endometrial cancers, oestrogen-dependent cancers and endometrioid adenocarcinoma compared with girls with a BMI $z$-score of 0 (Figure 1; Supplementary Table 2). Adjusting these associations for height only slightly attenuated the risk estimates (Supplementary Table 3). In contrast, BMI values below 0 were not associated with these cancers (Figure 1; Supplementary Tables 2 and 3). Few women were diagnosed with non-oestrogen-dependent cancers, and even though positive and statistically significant associations with childhood BMI were found at ages 12 and 13 years, the confidence intervals were wide (Table 2).

Childhood height was significantly positively associated with all endometrial cancers, oestrogen-dependent cancers and endometrioid adenocarcinoma (Figure 2; Supplementary Table 4). Adjusting for childhood BMI slightly attenuated the associations, but they remained statistically significant (Figure 2; Supplementary Table 4). Childhood height was non-significantly, but positively associated with non-oestrogen-dependent endometrial cancers (Figure 2; Supplementary Table 4).

We investigated whether unopposed oestrogen usage modified the associations between childhood body size and endometrioid adenocarcinoma. Of the 140044 women followed from 1995 
Table 1. Specification of endometrial cancers

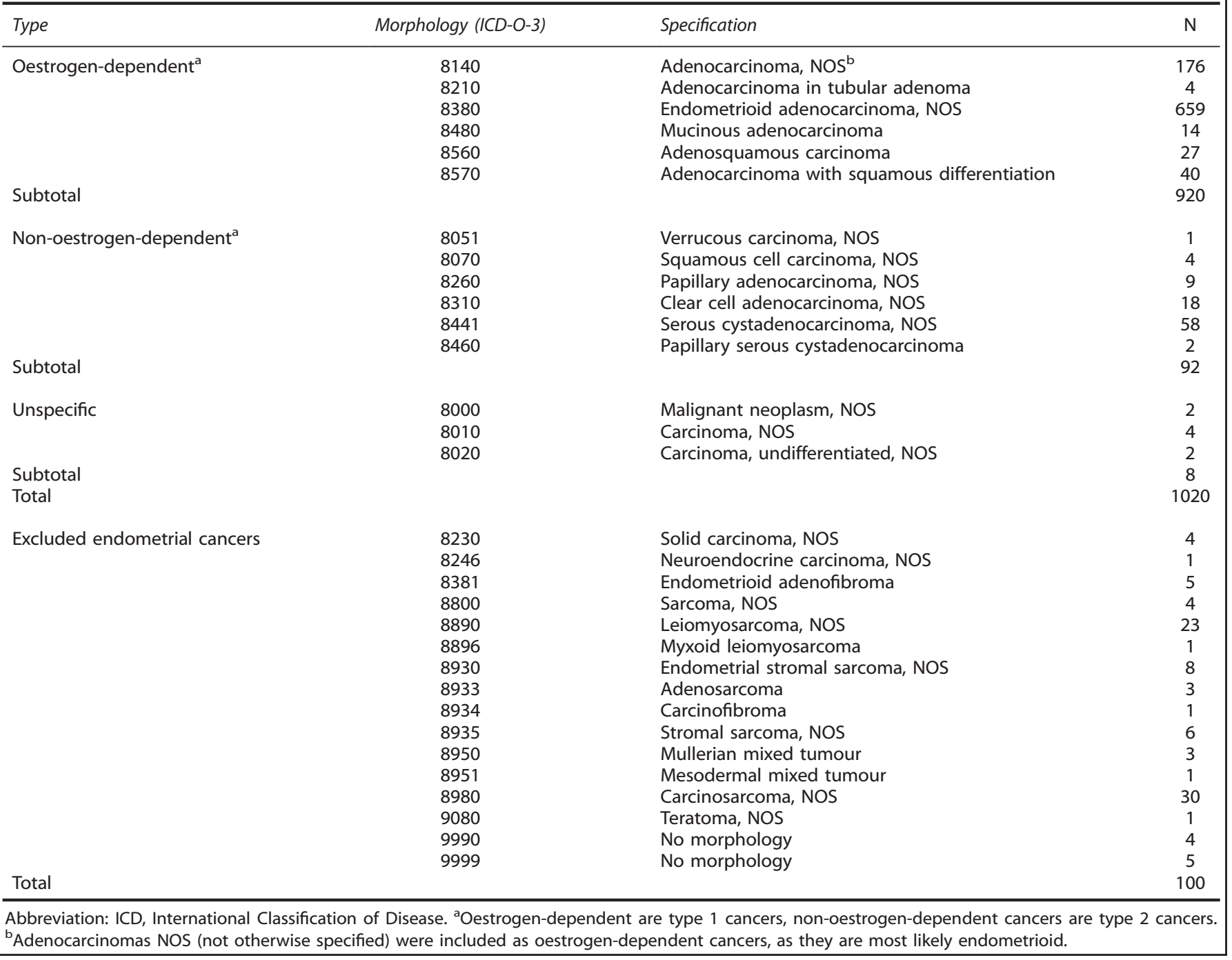

onwards, 8278 used unopposed oestrogens. There were 534 endometrioid adenocarcinomas among non-users and 74 among users of unopposed oestrogens. In this subsample, results were similar to those in the full-sample analyses on childhood BMI and endometrioid adenocarcinomas (Table 3; Supplementary Table 5). Among non-users of unopposed oestrogens, the estimates in analyses unadjusted and adjusted for height seemed to strengthen, but the overall pattern of associations did not change (Table 3; Supplementary Table 5). Correspondingly, in this subsample, the childhood height associations were similar to those in the full sample (Supplementary Table 6). Among nonusers of unopposed oestrogens, the estimates between childhood height and endometrioid adenocarcinoma were not affected (Supplementary Table 6).

\section{DISCUSSION}

In this large prospective cohort study, we found that girls with a BMI value above average at each age from 7 to 13 years experienced a significantly higher risk of all endometrial cancers, oestrogen-dependent cancers and the oestrogen-dependent subtype of endometrioid adenocarcinoma compared with girls of average size, whereas associations were not found among girls with $\mathrm{BMI}$ values below average. In contrast, associations between childhood BMI and non-oestrogen-dependent cancers were not identified except at ages 12-13 years and confidence intervals were broad. Childhood height was significantly and positively associated with all endometrial cancers, oestrogen-dependent cancers and endometrioid adenocarcinoma, but not with nonoestrogen-dependent cancers. Among non-users of unopposed oestrogens, associations between BMI and endometrioid adenocarcinoma seemed to strengthen, but there was little effect on the height associations.

Findings from other studies on early-life body size have been inconsistent. In all studies investigating body size early in life in relation to later risk of endometrial cancer, body size was retrospectively recalled; this may partly explain the equivocal findings for both body size ${ }^{15-24}$ and height. ${ }^{19,21,23}$ Furthermore, none of the studies evaluated if the associations differed by histologic subtypes of endometrial cancer and they primarily focused on body size in late adolescence making direct comparisons difficult. We found that childhood BMI was non-linearly associated with the risk of endometrial cancer. Although studies on childhood body size have not found similar non-linear effects, several studies on adult BMI have found that associations were stronger or limited to women with a BMI $>27-30 \mathrm{~kg} \mathrm{~m}^{-2}, 1,4,6,33,34$ whereas evidence suggests that associations with adult height are linear. Thus, these findings together with ours suggest that adiposity may be especially associated with endometrial cancer risk among females with a high level of adiposity. 
All
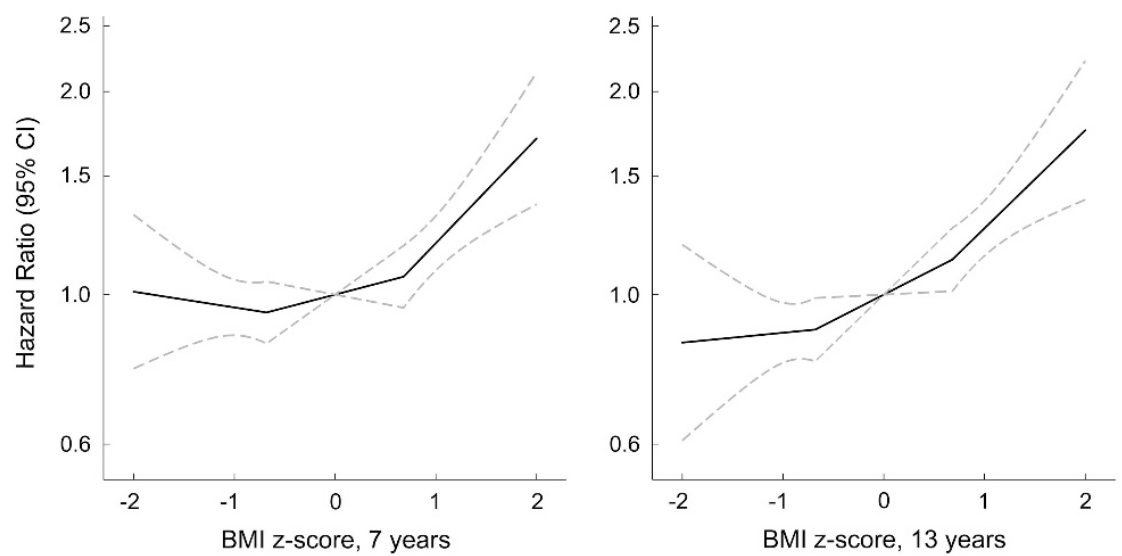

\section{Oestrogen- dependent}
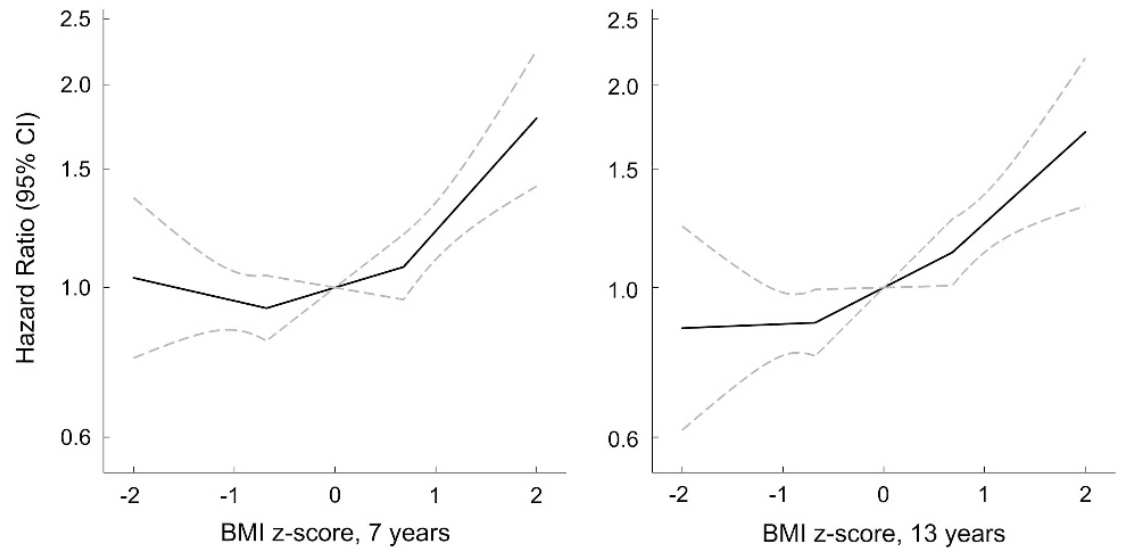

\section{Endometriod adenocarcinoma}
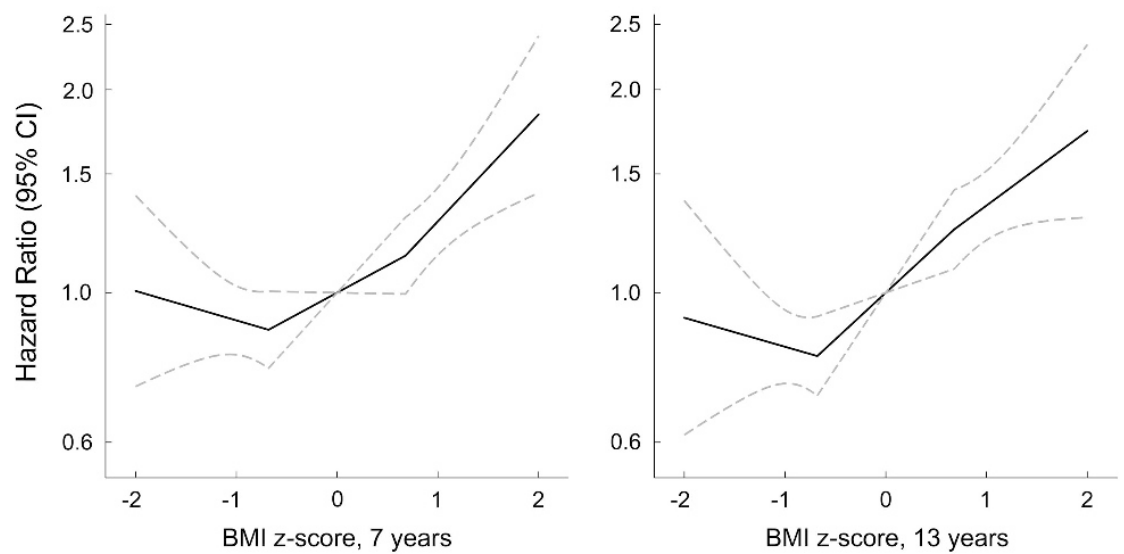

Figure 1. Hazard ratios (solid lines) and $95 \%$ confidence intervals (dotted lines) for the non-linear association between childhood BMI at ages 7 and 13 years, respectively, and the risk of all endometrial cancers, oestrogen-dependent cancers and endometrioid adenocarcinomas (Cox model stratified by 5-year birth cohorts. BMI was modelled using linear splines with two knots at $z$-scores of \pm 0.68 ).

In the adult literature, the vast majority of studies do not classify endometrial cancer by oestrogen dependency. Among studies distinguishing between oestrogen-dependent (type 1) and nonoestrogen-dependent (type 2) endometrial cancers, various definitions used are likely to contribute to some inconsistencies. Excess adult adiposity was positively associated with both types of endometrial cancers in some studies, nevertheless being most pronounced for oestrogen-dependent cancers. 7,10,35,36 Similarly, adult height has also been associated with both types of endometrial cancers, but again stronger associations were observed with oestrogen-dependent cancers. ${ }^{35}$ We did not observe any associations between childhood body size and non- oestrogen-dependent cancers. Non-oestrogen-dependent cancers are relatively uncommon, and in some studies grade 3 endometrioid cancers, which are oestrogen dependent, are also included in this classification. This may have created spurious findings in the adult studies.

Unopposed oestrogen use increases the risk of endometrial cancer. $^{13,37}$ In sub-analyses including only non-users of unopposed oestrogens, the shape of the associations between childhood BMI and endometrioid adenocarcinoma remained similar but the effect size seemed to increase as compared with the analyses that did not account for unopposed oestrogen usage. These results are consistent with the finding that the burden of 
Table 2. Childhood BMI and the risk of non-oestrogen-dependent endometrial cancer per BMl $z$-score ${ }^{a}$

\begin{tabular}{|c|c|c|c|c|c|c|}
\hline \multirow[t]{2}{*}{$\begin{array}{l}\text { Age } \\
\text { (years) }\end{array}$} & \multirow[t]{2}{*}{$\mathrm{N}$} & \multirow[t]{2}{*}{ Cases } & \multicolumn{2}{|c|}{$B M I$} & \multicolumn{2}{|c|}{$\begin{array}{c}\text { BMI adjusted for } \\
\text { height }\end{array}$} \\
\hline & & & $\begin{array}{c}\text { Hazard } \\
\text { ratios }\end{array}$ & $\begin{array}{c}95 \% \\
\text { confidence } \\
\text { intervals }\end{array}$ & $\begin{array}{c}\text { Hazard } \\
\text { ratios }\end{array}$ & $\begin{array}{c}95 \% \\
\text { confidence } \\
\text { intervals }\end{array}$ \\
\hline 7 & 145406 & 84 & 1.03 & $0.81-1.30$ & 1.00 & $0.78-1.27$ \\
\hline 8 & 147098 & 86 & 1.17 & $0.92-1.49$ & 1.15 & $0.90-1.48$ \\
\hline 9 & 142094 & 85 & 1.13 & $0.89-1.45$ & 1.11 & $0.86-1.42$ \\
\hline 10 & 138587 & 87 & 1.23 & $0.97-1.57$ & 1.20 & $0.94-1.55$ \\
\hline 11 & 137678 & 86 & 1.25 & $0.97-1.60$ & 1.23 & $0.95-1.59$ \\
\hline 12 & 136614 & 86 & 1.30 & $1.02-1.66$ & 1.30 & $1.01-1.68$ \\
\hline 13 & 134707 & 88 & 1.31 & $1.03-1.66$ & 1.31 & $1.02-1.68$ \\
\hline
\end{tabular}

Abbreviation: $\mathrm{BMI}$, body mass index. ${ }^{\mathrm{a}} \mathrm{Cox}$ model stratified by 5 -year birth cohorts.

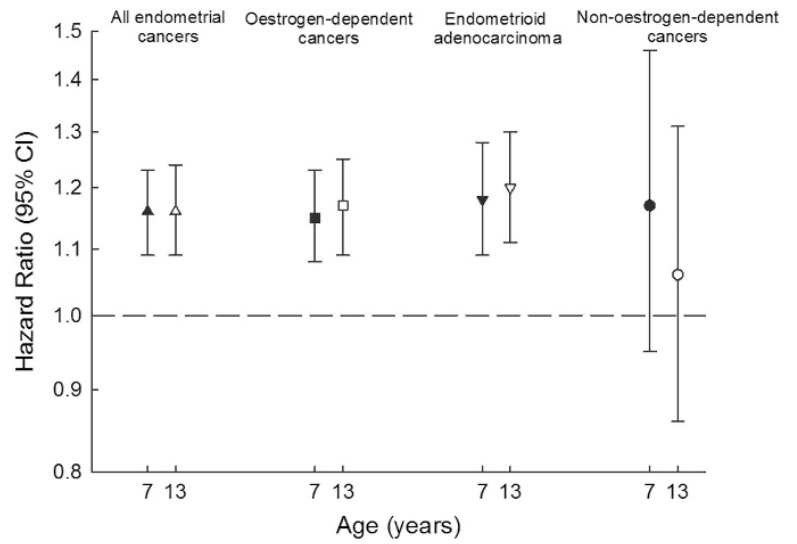

Figure 2. Childhood height and the risk of all endometrial cancers, oestrogen-dependent cancers, endometrioid adenocarcinomas and non-oestrogen-dependent cancers per $z$-score unadjusted (black symbols) and adjusted (white symbols) for BMI (Cox model stratified by 5-year birth cohorts).

endometrial cancer attributable to excess adult adiposity is significantly higher among non-oestrogen users compared with ever users. ${ }^{8}$ It is thought that exogenous oestrogens elevate circulating levels to such an extent that endogenous oestrogens produced by adipose tissue only have a limited additional influence on the risk of endometrial cancer. ${ }^{1,34}$ Associations between height and endometrioid adenocarcinoma did not change in analyses including only non-users of unopposed oestrogens as expected. Results from studies on childhood body size and endometrial cancer risk that adjusted for hormone replacement therapy use are inconsistent, and as they did not specifically investigate unopposed oestrogens, direct comparisons with our study are limited. ${ }^{16,17,21,22}$

The unopposed oestrogen hypothesis is the prevailing theory explaining associations between adiposity and endometrial cancer risk. Adiposity may favour endometrial carcinogenesis through a greater expression of aromatase increasing the production of oestrogens with mitogenic effects. ${ }^{13,38}$ It is proposed that this biological mechanism is particularly relevant among postmenopausal women, where ovarian production of oestrogens and progesterones has ceased. ${ }^{13,38}$ Among premenopausal women, the obesity-related increase in ovarian androgen production inducing a chronic anovulation leading to progesterone deficiency might be most important for endometrial carcinogenesis. $^{13,38}$ In our study, we do not suspect that the

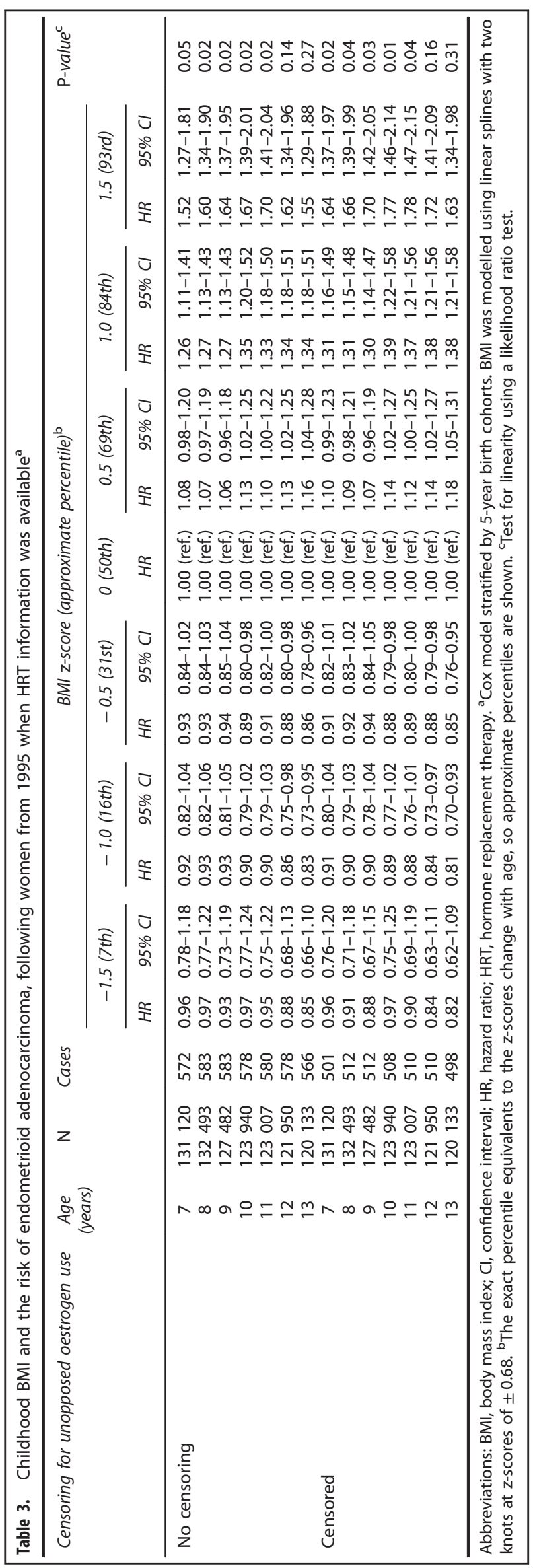


associations with childhood body size differ by menopausal state, as the associations were the same across adult ages.

The underlying mechanisms for an association between childhood height and endometrial cancer risk are unknown; however, height is a biological marker of various genetic, environmental, hormonal and nutritional factors associated with linear growth in childhood. ${ }^{1}$ Nevertheless, independent of the unknown mechanisms for these associations, our findings emphasise that endometrial carcinogenesis may have its origins early in life.

In our study, we examined only the associations of child size with endometrial cancer risk as information on adult size was unavailable. It is likely that our findings reflect an admixture of effects of childhood body size itself and the effects of size that tracks into adult life. ${ }^{39}$ We found that the strength of the BMI and height associations were relatively constant across childhood ages with the exception of non-oestrogen-dependent endometrial cancers (although the confidence intervals were broad). As size at 13 years of age is more proximal in time to adult size than earlier size, it is expected that the associations at age 13 years would be stronger than at 7 years if tracking entirely explained these results. One study using recalled body size (somatotype drawings) at age 10 years with self-reported information on hysterectomy and HRT use found that associations with postmenopausal endometrial cancer largely disappeared after adjusting for adult BMI. $^{24}$ Even though we cannot disentangle the potential effects of tracking, our findings are important for identifying girls who may be at later risk of developing endometrial cancer.

The major strengths of this study include the mandatory health exams with measurements of heights and weights among a large group of school children. In addition, we had almost complete long-term follow-up and due to the comprehensive Danish registers we had extensive pathology information on a large number of endometrial cancers making us able to classify cancers based on their oestrogen dependency. Our study might, however, be limited by not having information available on the age at menarche and menopause, as a woman's life-long number of ovulatory cycles affects her risk of developing endometrial cancer through the duration of exposure to endogenous sex hormones. ${ }^{40}$ We examined associations based upon single body size measures; it was beyond the scope of this study to incorporate multiple measures and investigate growth in relation to endometrial cancer.

To put our results into perspective, we calculated PAFs, which estimate the burden of endometrial cancers attributable to childhood adiposity. In our population of girls with far lower levels of overweight and obesity than contemporary girls, the PAF of overweight (including obesity) of endometrioid adenocarcinomas was $4.0 \%$ at the age of 7 years and $3.7 \%$ at the age of 13 years. When extrapolating our findings using levels of overweight and obesity among girls in the latest US National Health and Nutrition Examination Survey in 2011-2012 (35\% and 34\% overweight or obese at ages 6-11 years and 12-19 years, respectively), the PAF of overweight (including obesity) of endometrioid adenocarcinomas was $22.3 \%$ at age 7 years and $19.8 \%$ at age 13 years. ${ }^{41}$ These values resemble the PAF estimated for adult overweight and obesity of $34 \% .^{8}$ Assuming a causal relationship, these estimates suggest there will be a tremendous increase in numbers of future endometrial cancers given the current high levels of childhood overweight and obesity, nonetheless, the estimates should be interpreted cautiously.

In conclusion, these results demonstrate that a greater childhood body size is significantly and positively associated with the future risk of being diagnosed with endometrial cancer, particularly the oestrogen-dependent types. However, potential mechanisms for these associations with childhood body size warrant further investigation. Even though most oestrogen-dependent endometrial cancers have a good prognosis, women diagnosed with this disease suffer from impaired physical and psychological health, thus supporting efforts for the early identification of individuals at later risk of endometrial cancers to reduce the occurrence of this disease.

\section{CONFLICT OF INTEREST}

The authors declare no conflict of interest.

\section{ACKNOWLEDGEMENTS}

We are appreciative of the efforts required to build the Copenhagen School Health Records Register, which has been established in collaboration between the Institute of Preventive Medicine and the Copenhagen City Archive. Funding: The research leading to these results has received funding from the European Research Council under the European Union's Seventh Framework Programme (FP/2007-2013)/ERC Grant Agreement (no. 281419, childgrowth2cancer) to JLB.

\section{REFERENCES}

1 World Cancer Research Fund / American Institute for Cancer Research. Continuous Update Project Report. Food, Nutrition, Physical Activity, and the Prevention of Endometrial Cancer, 2015. Available at http://www. dietandcancerreport.org (accessed August 2015).

2 Globocan. Estimated Cancer Incidence, Mortality and Prevalence Worldwide in 2012. International Agency on Cancer (IARC). World Health Organization (WHO), 2015. Available at http://globocan.iarc.fr/ (accessed August 2015).

3 NORDCAN, Association of the Nordic Cancer Registries. (Cancer Statistics), 2015. Available at http://www-dep.iarc.fr/nordcan.htm (accessed August 2015).

4 Aune D, Navarro Rosenblatt DA, Chan DS, Vingeliene S, Abar L, Vieira AR et al. Anthropometric factors and endometrial cancer risk: a systematic review and dose-response meta-analysis of prospective studies. Ann Oncol 2015; 26: 1635-1648.

5 Bhaskaran K, Douglas I, Forbes H, dos-Santos-Silva I, Leon DA, Smeeth L. Bodymass index and risk of 22 specific cancers: a population-based cohort study of 5.24 million UK adults. Lancet 2014; 384: 755-765.

6 Reeves GK, Pirie K, Beral V, Green J, Spencer E, Bull D. Cancer incidence and mortality in relation to body mass index in the Million Women Study: cohort study. BMJ 2007; 335: 1134.

7 McCullough ML, Patel AV, Patel R, Rodriguez C, Feigelson HS, Bandera EV et al. Body mass and endometrial cancer risk by hormone replacement therapy and cancer subtype. Cancer Epidemiol Biomarkers Prev 2008; 17: 73-79.

8 Arnold M, Pandeya N, Byrnes G, Renehan AG, Stevens GA, Ezzati M et al. Global burden of cancer attributable to high body-mass index in 2012: a populationbased study. Lancet Oncol 2015; 16: 36-46.

9 Horn LC, Meinel A, Handzel R, Einenkel J. Histopathology of endometrial hyperplasia and endometrial carcinoma: an update. Ann Diagn Pathol 2007; 11: 297-311.

10 Yang HP, Wentzensen N, Trabert B, Gierach GL, Felix AS, Gunter MJ et al. Endometrial cancer risk factors by 2 main histologic subtypes: the NIH-AARP diet and health Study. Am J Epidemiol 2013; 177: 142-151.

11 Felix AS, Weissfeld JL, Stone RA, Bowser R, Chivukula M, Edwards RP et al. Factors associated with Type I and Type II endometrial cancer. Cancer Causes Control 2010; 21: 1851-1856.

12 Danish Gynecological Cancer Group. Danish Gynecological Cancer Database National Annual Report 2013/2014: Nationwide Clinical Database for Cancer of the Ovaries, Uterus and Cervix [Dansk Gynækologisk Cancer Database National Årsrapport 2013/2014: Landsdækkende klinisk database for kræft i æggestokke, livmoder og livmoderhals], 2015. Available at http://www.dgcg.dk/images/rsrap port_DGCD_2013-14_endelig\%20version.pdf (accessed August 2015).

13 Kaaks R, Lukanova A, Kurzer MS. Obesity, endogenous hormones, and endometrial cancer risk: a synthetic review. Cancer Epidemiol Biomarkers Prev 2002; 11: 1531-1543.

14 Green J, Cairns BJ, Casabonne D, Wright FL, Reeves G, Beral V. Height and cancer incidence in the Million Women Study: prospective cohort, and meta-analysis of prospective studies of height and total cancer risk. Lancet Oncol 2011; 12: 785-794.

15 Blitzer PH, Blitzer EC, Rimm AA. Association between teen-age obesity and cancer in 56,111 women: all cancers and endometrial carcinoma. Prev Med 1976; 5: 20-31.

16 Chang SC, Lacey Jr JV, Brinton LA, Hartge P, Adams K, Mouw T et al. Lifetime weight history and endometrial cancer risk by type of menopausal hormone use in the NIH-AARP diet and health study. Cancer Epidemiol Biomarkers Prev 2007; 16: 723-730. 
17 Dal ML, Tavani A, Zucchetto A, Montella M, Ferraroni M, Negri E et al. Anthropometric measures at different ages and endometrial cancer risk. $\mathrm{Br} J$ Cancer 2011; 104: 1207-1213.

18 Henderson BE, Casagrande JT, Pike MC, Mack T, Rosario I, Duke A. The epidemiology of endometrial cancer in young women. Br J Cancer 1983; 47: 749-756.

19 Le Marchand L, Wilkens LR, Mi MP. Early-age body size, adult weight gain and endometrial cancer risk. Int J Cancer 1991; 48: 807-811.

20 Olson SH, Trevisan M, Marshall JR, Graham S, Zielezny M, Vena JE et al. Body mass index, weight gain, and risk of endometrial cancer. Nutr Cancer 1995; 23: 141-149.

21 Swanson CA, Potischman N, Wilbanks GD, Twiggs LB, Mortel R, Berman ML et al. Relation of endometrial cancer risk to past and contemporary body size and body fat distribution. Cancer Epidemiol Biomarkers Prev 1993; 2: 321-327.

22 Weiderpass E, Persson I, Adami HO, Magnusson C, Lindgren A, Baron JA. Body size in different periods of life, diabetes mellitus, hypertension, and risk of postmenopausal endometrial cancer (Sweden). Cancer Causes Control 2000; 11: 185-192.

23 Xu WH, Xiang YB, Zheng W, Zhang X, Ruan ZX, Cheng JR et al. Weight history and risk of endometrial cancer among Chinese women. Int J Epidemiol 2006; 35: 159-166.

24 Yang TY, Cairns BJ, Allen N, Sweetland S, Reeves GK, Beral V. Postmenopausal endometrial cancer risk and body size in early life and middle age: prospective cohort study. Br J Cancer 2012; 107: 169-175.

25 Baker JL, Olsen LW, Andersen I, Pearson S, Hansen B, Sørensen TIA. Cohort profile: the Copenhagen School Health Records Register. Int J Epidemiol 2009; 38: 656-662.

26 Pedersen CB. The Danish Civil Registration System. Scand J Public Health 2011; 39: 22-25.

27 Cole TJ, Green PJ. Smoothing reference centile curves: the LMS method and penalized likelihood. Stat Med 1992; 11: 1305-1319.

28 Baker JL, Olsen LW, Sørensen TIA. Childhood body-mass index and the risk of coronary heart disease in adulthood. N Engl J Med 2007; 357: 2329-2337.

29 Gjerstorff ML. The Danish Cancer Registry. Scand J Public Health 2011; 39: 42-45.

30 Storm HH, Michelsen EV, Clemmensen IH, Pihl J. The Danish Cancer Registryhistory, content, quality and use. Dan Med Bull 1997; 44: 535-539.

31 Lynge E, Sandegaard JL, Rebolj M. The Danish National Patient Register. Scand J Public Health 2011; 39: 30-33.
32 Kildemoes HW, Sorensen HT, Hallas J. The Danish National Prescription Registry. Scand J Public Health 2011; 39: 38-41.

33 Renehan AG, Soerjomataram I, Tyson M, Egger M, Zwahlen M, Coebergh JW et al. Incident cancer burden attributable to excess body mass index in 30 European countries. Int J Cancer 2010; 126: 692-702.

34 Crosbie EJ, Zwahlen M, Kitchener HC, Egger M, Renehan AG. Body mass index, hormone replacement therapy, and endometrial cancer risk: a meta-analysis. Cancer Epidemiol Biomarkers Prev 2010; 19: 3119-3130.

35 Bjørge T, Engeland A, Tretli S, Weiderpass E. Body size in relation to cancer of the uterine corpus in 1 million Norwegian women. Int J Cancer 2007; 120: 378-383.

36 Setiawan VW, Yang HP, Pike MC, McCann SE, Yu H, Xiang YB et al. Type I and II endometrial cancers: have they different risk factors? J Clin Oncol 2013; 31: 2607-2618.

37 Grady D, Gebretsadik T, Kerlikowske K, Ernster V, Petitti D. Hormone replacement therapy and endometrial cancer risk: a meta-analysis. Obstet Gynecol 1995; 85: 304-313.

38 Calle EE, Kaaks R. Overweight, obesity and cancer: epidemiological evidence and proposed mechanisms. Nat Rev Cancer 2004; 4: 579-591.

39 Power C, Lake JK, Cole TJ. Body mass index and height from childhood to adulthood in the 1958 British born cohort. Am J Clin Nutr 1997; 66: 1094-1101.

40 Purdie DM, Green AC. Epidemiology of endometrial cancer. Best Pract Res Clin Obstet Gynaecol 2001; 15: 341-354.

41 Ogden CL, Carroll MD, Kit BK, Flegal KM. Prevalence of childhood and adult obesity in the United States, 2011-2012. JAMA 2014; 311: 806-814.

This work is licensed under a Creative Commons AttributionNonCommercial-NoDerivs 4.0 International License. The images or other third party material in this article are included in the article's Creative Commons license, unless indicated otherwise in the credit line; if the material is not included under the Creative Commons license, users will need to obtain permission from the license holder to reproduce the material. To view a copy of this license, visit http:// creativecommons.org/licenses/by-nc-nd/4.0/

Supplementary Information accompanies this paper on International Journal of Obesity website (http://www.nature.com/ijo) 